\title{
How does Entrepreneurial Education Influence the Entrepreneurial Intention of College Students: The Moderating and Mediating Effects of Entrepreneurial Alertness
}

\author{
https://doi.org/10.3991/ijet.v14i08.10408 \\ Dapeng Sang $(\bowtie)$ \\ Wenzhou Business College, WenZhou, China \\ $00201110 @ \mathrm{wzbc} . \mathrm{edu} . \mathrm{cn}$ \\ Jinyan Lin \\ Yango University, Fuzhou, China
}

\begin{abstract}
The relation between college students' entrepreneurial intention and college entrepreneurial education has long been concerned. Entrepreneurial alertness is the psychological basis for entrepreneur to identify entrepreneurial opportunities. Entrepreneurial intention and entrepreneurial alertness are two key focuses in entrepreneurship research. It is of great significance to explore and investigate the role of entrepreneurial alertness in arousal process of entrepreneurial intention by entrepreneurial education. However, there are very few researches reported on the relation among entrepreneurial education, entrepreneurial alertness and entrepreneurial intention. Entrepreneurial education was measured by the Benefits from Entrepreneurial Education Programes (BEEP). By collecting data $(\mathrm{N}=672)$ from colleges and universities in Zhejiang and Fujian where entrepreneurship is relatively active in China, empirical study was carried out to investigate the relation among the three variables. The results showed that: entrepreneurial alertness plays a significant mediating and regulating role between entrepreneurial education and entrepreneurial intention. The cultivation of entrepreneurial alertness should be a key purpose of entrepreneurial education. Finally, this paper presents discussion on how to conduct targeted entrepreneurial education in order to guide college students' entrepreneurship more efficiently.
\end{abstract}

Keywords-Entrepreneurial education; entrepreneurial alertness; entrepreneurial; universities and colleges

\section{$1 \quad$ Introduction}

Innovative entrepreneurial activities are crucial for transforming scientific technology into productivity and can promote economic restructuring as well as generate new economic growth points (Schumpeter, 1936). Since 2010, China has been facing the two major challenges of employment pressure and finding new economic growth 
points. According to relevant statistics, the number of college graduates in China from 2014 to 2017 reached 7.27 million, 7.49 million, 7.56 million, and 7.95 million respectively, continuously hitting record highs. This is followed by the aggravating employment pressure. Employment is the foundation of people's livelihood, and entrepreneurship is the source of employment (Fu et al., 2010). Practical examples of the developed countries in the West have shown that innovative entrepreneurial activities can create a significant number of new job opportunities. In terms of new economic growth, the State Council Government Work Report in 2015 identified "Mass entrepreneurship and innovation" (Double Creations) as one of the "double engines," which drive economic development. As the valuable carriers of human capital, the college students who have received higher education should be the ones to shoulder this great responsibility. Drucker (1985) believed that entrepreneurship can be taught. Entrepreneurial education is able to cultivate an individual's sense of innovation and entrepreneurial spirit, thereby improving his or her quality of entrepreneurship (Clark, Brian, Charles et al., 1984). Thus, it has become a historical trend to implement entrepreneurial education in colleges and universities. Over the past decade or so, the education sector in China has dedicated itself to promoting the development of entrepreneurial education and has achieved some results. However, there are still many issues that remain to be solved, such as the little interest among the students in entrepreneurship despite the large class sizes. Therefore, with the goal of encouraging college students to be entrepreneurial, it is necessary to study how to better promote entrepreneurial education.

Entrepreneurship is a planned and purposeful behaviour. According to the theory of planned behaviour, entrepreneurial intentions can be a good predictor of entrepreneurial behaviour (Ajzen, 1991; Souitaris, Zerbinati, Al-Laham, 2007). It is only possible for people with high entrepreneurial intentions to engage in entrepreneurial activities (Krueger, 2000). Therefore, a good entrepreneurial education will inevitably help to enhance entrepreneurial intentions. According to existing research, entrepreneurial education has a positive influence on entrepreneurial intentions (Kolvereid \& Moen, 1997; Tkachev \& Kolvereid, 1999; Souitaris, Zerbinati, Al-Laham, 2007; Leoni \& Falk, 2010). Many of these research studies explored entrepreneurial education as a whole, while only a few divided the concept into different aspects such as the content and the modes of teaching (Souitaris, Zerbinati, Al-Laham, 2007). In order to have an impact on the students'entrepreneurial activities,boththe content and the modes of teaching first have to be internalised into the students the benefits from Entrepreneurial Education Programes (BEEP). Therefore, this paper will refer to the research study of Souitaris, Zerbinati and Al-Laham (2007) to explore which variables are operating in the process of improving entrepreneurial intention with entrepreneurial education from the perspective of BEEP, in order to provide a clearer understanding as to how to better promote entrepreneurial education for college students.

Entrepreneurs often need to explore and analyse potential entrepreneurial opportunities, and to achieve entrepreneurial goals through utilizing the entrepreneurial opportunities by coordinating social, financial and material resources. Entrepreneurial intentions reflect the tendency of individuals to be willing to engage in entrepreneurial activities. Thus, it can be said that opportunity recognition is the basis for generating 
entrepreneurial intentions. Previous research has shown that opportunity recognition is closely related to entrepreneurial alertness. Entrepreneurial alertness was first proposed by Kirzner (1979) and was defined as the ability to perceive hitherto overlooked opportunities without searching for them. This definition is widely acknowledged by most scholars, and laid the foundation for research on opportunity recognition. Researchers also generally agree that entrepreneurial alertness can significantly promote opportunity discovery (Wei, 2009).Some researchers (Glaglio \& Katz, 2001) directly equate entrepreneurial alertness to the psychological basis of opportunity discovery.

Consequently, Wei (2009) believed that for enterprises, prompting the entrepreneurial team to acquire higher entrepreneurial alertness should be an important objective in the entrepreneurial process. Hence, this paper believes that for colleges and universities, prompting students to acquire higher entrepreneurial alertness should be an important objective in entrepreneurial education.

Summing up the aforementioned practical and theoretical background, it is of great importance to explore the implementation route between collegial entrepreneurial education and entrepreneurial intentions. Yet, with both being the prerequisites for entrepreneurial behaviour, what is the relationship between entrepreneurial alertness and entrepreneurial intentions? What is the role of entrepreneurial alertness in the process of enhancing entrepreneurial intentions in entrepreneurial education? How does one analyse the relationship between entrepreneurial education, entrepreneurial intentions and entrepreneurial alertness? Such questions have rarely been addressed in existing research.

To preliminarily logically analyse the questions above, entrepreneurial alertness is closely related to opportunity recognition, while opportunity recognition is tied to various types of entrepreneurial knowledge, which means entrepreneurial education affects entrepreneurial alertness. Moreover, entrepreneurial alertness influences the value judgement of entrepreneurial behaviour through opportunity recognition, which could subsequently influence entrepreneurial intentions. Therefore, entrepreneurial alertness could have a mediating effect between entrepreneurial education and entrepreneurial intentions. Individuals with high entrepreneurial alertness possess higher opportunity sensitivity, meaning that they are more likely to perceive a potential opportunity from the same piece of information compared to others. Consequently, individuals with different levels of entrepreneurial alertness will generate different levels of entrepreneurial intentions even if they received the same entrepreneurial education. After the preliminary logical analysis, is it possible to construct a normative theoretical hypothesis based on existing studies and test it empirically? These are the research objectives of this paper.

Thus the specific research objectives of this paper are threefold: First, to examine the relationship between entrepreneurial education, entrepreneurial intentions and entrepreneurial alertness; second, to test the mediating effect of entrepreneurial alertness between entrepreneurial education and entrepreneurship education; third, to test the moderating effect of entrepreneurial alertness on the relationship between entrepreneurial education and entrepreneurial intentions. The presupposed theoretical model of this paper is shown in Figure 1. 




Fig. 1. Theoretical Presupposition

This paper attempts to make a theoretical contribution towards constructing a more comprehensive entrepreneurial education system through the abovementioned research objectives.

\section{Theoretical Framework and Hypotheses}

The entrepreneurial intentions model and the theory of planned behaviour are widely applied in the analysis ofentrepreneurial intentions and behaviour (Elfving et al., 2009). This paper will also use these two theories as the foundation in combination with previous studies to develop theoretical discussions on the hypothesis of this paper.

\subsection{Entrepreneurial education and entrepreneurial intentions}

Entrepreneurial education provides students with entrepreneurship-related knowledge and skills training. According to the research of Gartner and Vesper (1994) on literature and the observations of Souitaris (2007) on mainstream universities, the content of an entrepreneurial education with a comprehensive and effective system can be categorised into four groups: content teaching; business plan training; interactive exchange or internship; and support from the educational institutions. According to Souitaris et al. (2007), there are three types of entrepreneurial program benefits to college students: knowledge acquisition, encouragement and incubation of resources.

Studies from many other scholars have shown that entrepreneurial education or entrepreneurship courses can significantly enhance the entrepreneurial intentions among college students (TKACHEV and KOLVEREID, 1999), (Noel, 2002), (Carayannis et al., 2003), (Souitaris et al., 2007), (Xiang, C. and Lei, 2011; Xiang, H. and Lei, 2014).

According to the theory of planned behaviour (Azjen, 1991), normative beliefs lead to subjective norms - the views and evaluation on something from a person's sur- 
roundings or influential people - which in turn generate intentions. Entrepreneurial education consists of the instillation of entrepreneurial spirit, the advocacy from the government, and the demonstration effects from successful enterprises and entrepreneurs, all of which enhance the students' normative beliefs and therefore facilitate the generation of entrepreneurial intentions.

According to Shapero's entrepreneurial intentions model, entrepreneurial intentions are influenced by the perceived feasibility and desirability of entrepreneurship, while perceived feasibility and desirability are influenced by the breadth of entrepreneurial experience. The breadth of entrepreneurial experience refers to the various direct and indirect entrepreneurial experiences of an individual (Krueger, 1993). The theoretical teaching of entrepreneurial education consists of a large number of case studies as well as the experience sharing of successful entrepreneurs, while the practical teaching includes internship experience. All of these provide abundant indirect experiences; hence entrepreneurial education will promote entrepreneurial intentions.

Thus, this paper proposes the following research hypothesis:

H1: Entrepreneurial education positively promotes the generation of entrepreneurial intentions.

\subsection{The mediating effect of entrepreneurial alertness between entrepreneurial education and entrepreneurial intentions}

Regardless of whether it is curriculum teaching, skills training or practical teaching, the important outcome of entrepreneurial education is to transfer different types of the processes practical knowledge necessary for entrepreneurship to students.

Studies conducted by Chinese and foreign researchers showed that acquiring diverse knowledge has a significant effect on enhancing opportunity recognition. Such knowledge consists of existing knowledge, a priori knowledge and specialised knowledge. It was proven that individuals with a deep knowledge base have a higher sensitivity to potential and promising opportunities (Smith et al., 2009; Tang et al., 2012). The research by Wang and Lu (2015) showed that existing knowledge plays a significant role in enhancing opportunity recognition. Li, G. and Li, N. (2014) proved that a priori knowledge is positively correlated with entrepreneurial alertness. A priori knowledge is the entrepreneurial knowledge that the entrepreneur has already accumulated, and one of the crucial ways for such accumulation is entrepreneurial education.

Regarding specialised knowledge, Mitchell et al. (2000) referred to this type of knowledge as expert scripts, and proved in his studies the significant impacts expert scripts have on opportunity recognition. And the acquisition and refinement of specialised knowledge, also known as expert scripts, is the main task of entrepreneurial education.

Gimeno et al. (1997) pointed out that previous entrepreneurial training activities, experience or skills would form a broad cognitive framework of information links that would help the brain to recognise possible opportunities, which again emphasised the central role of entrepreneurial education. 
On the other hand, recognising and discovering opportunities are the core of entrepreneurial alertness (Tang et al., 2012; Uy et al., 2015).

Studies by Ko and Butler (2007) also showed that the internal knowledge base, external mature social networks, andthe high attentiveness towards entreprenuerial opportunities of an individual directly affect the generation of entreprenuerial alertness. And referring to the aforementioned definition of entrepreneurial education, the construction of either or both knowledge base and external social networks is the content of entrepreneurial education (to be acquired).

Thus, to summarise, entreprenuerial education has a positive promoting effect on entrepreneurial awareness.

Recapping the theory of planned behaviour proposed by Azjen (1991), first beliefs influence attitudes, which in turn influence intentions, which finally lead to behaviours.

In the theory of planned behaviour, beliefs include the judgements and expectations of value, while attitudes include behavioural attitudes. The theory of planned behaviour indicates that behaviour attitudes are influenced by the expected value, and are an individual's evaluation of the behavioural outcome, as in whether the individual likes or dislikes, or deems it valuable or otherwise(Jr et al., 2000). According to the theory of planned behaviour, the expected value promotes the generation of intentions through behavioural attitudes.

Entrepreneurial alertness enables one to assess whether attractive opportunities can emerge (Ma and Huang, 2016; Tang et al., 2012). Therefore, entrepreneurial alertness creates in people an expected value for potential opportunities, and the expected value for potential entrepreneurial opportunities in turn generates the behavioural attitudes towards entrepreneurship, eventually resulting in the emergence of entrepreneurial intentions.

Additionally, in their study on university students abroad, Tian and Wang (2011) found out that a number of personal traits including the ability to recognise opportunities have a greater influence on entrepreneurial intentions. Meanwhile, opportunity recognition is the core of entrepreneurial alertness.

Summing up, this paper proposes a second research hypothesis:

H2: Entrepreneurial alertness has a mediating effect in the relationship between entrepreneurial education and entrepreneurial intentions.

\subsection{The moderating effect of entrepreneurial alertness between entrepreneurial education and entrepreneurial intentions}

According to Shapero's entrepreneurial intentions model, the perceived feasibility and desirability of entrepreneurship will influence entrepreneurial intentions. The perception of the attractiveness of a business opportunity is the perceived entrepreneurial desirability(Krueger, 1993). Entrepreneurial alertness is the recognition of a potential business opportunity (Kirzner, 1979), and is a sensitive and timely judgment (Gaglio and Katz, 2001). Individuals with high alertness are able to maximise the possibility of realising the opportunity (Kaish and Gilad, 1991), a conclusion similarly shared by Li (2013). This means that entrepreneurs with high entrepreneurial alert- 
ness are more sensitive to information when they receive entrepreneurial education, and are more likely to discover hidden business opportunities and sense the "appeal" among the seemingly "ordinary" information. Therefore when an individual possesses high entrepreneurial alertness, his or her desirability of entrepreneurship is higher, and for such individual the same entrepreneurial education can provide higher entrepreneurial intentions.

At the same time, according to the entrepreneurial intentions model, the perceived desirability of entrepreneurship is dependent on the entrepreneur's active cognition of entrepreneurial experience, which is the extent to which the individual actively and positively interprets his or her entrepreneurial experience. Even of a failed experience, the entrepreneur can still make positive interpretations, see the bright side of things and turn it into a positive experience, there by gaining a valuable experience and lesson, and boosting the entrepreneur's self-confidence (Krueger, 1993). Kirzner (1985) pointed out that alertness is a "tendency to envision the future positively". Therefore, individuals with high entrepreneurial alertness will have a positive interpretation of the direct and indirect experiences provided by entrepreneurial education, thus achieving a higher perceived desirability of entrepreneurship and in turn stimulating the emergence of entrepreneurial intentions.

Additionally, according to the entrepreneurial intentions model, entrepreneurial intentions are also influenced by the perceived feasibility which originates from the breadth of entrepreneurial experience. Evans and Friedman (2011) believed that alert entrepreneurs can recognize profiting opportunities and know how to do so. Therefore, entrepreneurs with high entrepreneurial alertness are able to perceived a higher feasibility from the direct or indirect experiences provided by entrepreneurial education.

As a result, we can deduce that entrepreneurs with high entrepreneurial alertness receiving the same entrepreneurial education are able to generate higher entrepreneurial intentions.

Hence, this paper proposes the following hypothesis:

H3: Entrepreneurial alertness has a moderating effect between entrepreneurial education and entrepreneurial intentions.

\section{$3 \quad$ Research Methodology}

\subsection{Variable measurement}

In order to ensure the reliability and validity of the measurement tools, this study mainly used the maturity scale which was modified appropriately in accordance with the research objectives into a pre-testing questionnaire. A small number of the questionnaires were issued to conduct a pre-survey, the result of which led to the adjustment of certain wordings, resulting in the official questionnaire used for this study.

- For the measurement of entrepreneurial education, this study used the BEEP scales of Souitaris et al. (2007), which is divided into three aspects, namely knowledge 
acquisition, aspiration and encouragement, and resource utilisation, with a total of 21 questions. The reliability coefficient of this measurement scale is 0.928 , indicating that the scale has high reliability.

- For the measurement of entrepreneurial alertness, this paper used the measurement scale of Miao (2006), with a total of six questions. The reliability coefficient of this measurement scale is 0.795 , indicating that the scale has high reliability.

- The measurement scale of entrepreneurial intentions was modified from Thompson's (2009) measurement scale, with a total of six questions. The reliability coefficient of this measurement scale is 0.804 , indicating that the scale has high reliability.

- In addition, according to previous studies, a student's personalities, gender and hukou can influence his or her entrepreneurial alertness and entrepreneurial intentions. Therefore, this study treated these variables as control variables.

Apart from control variables, all other variables were scoredon aLikert 5-point scale, and were assigned values 1, 2, 3, 4, 5 from not-at-all accurate to completely accurate. Additionally, because control variables such as gender, hukou and personalities are categorical variables, this study converted these variables into dummy variables before testing the hypothesis. Among them, "gender dummy variables" was converted to "the comparison between female and male", "hukou dummy variables" was converted to "the comparison between urban and rural hukou,"and "personality dummy variables 1, 2, 3" was converted to the comparison between "somewhat introverted", "somewhat extroverted", "extroverted" and "introverted".

\subsection{Sampling}

In this study, a total of 872 questionnaires were issued to the matriculated college students in the provinces of Zhejiang and Fujian who have received entrepreneurial education. 753 of them were returned, resulting in a response rate of $86.35 \%$. After eliminating 81 unqualified entries, there were a total of 672 valid questionnaire responses, resulting in a completion rate of $89.24 \%$. Among them, the percentage of male and female respondents are $45.4 \%$ and $54.6 \%$ respectively; the gap between urban hukou and rural hukou respondents was not significant, sitting at $44.9 \%$ and $55.1 \%$ respectively; introverted, somewhat introverted, somewhat extroverted and extroverted respondents were at $22.5 \%, 28.3 \%, 25.7 \%$ and $23.5 \%$ respectively. Thus, it can be seen that the sample is to some extent representative.

\subsection{Single-source bias analysis}

Due to the fact that all questions in the questionnaire were filled out by the same subject, single-source bias may exist. Podsakoff and Organ (1986) proposed using Harman's single-factor test to test for single-source bias, which means conducting factor analysis on all questions on the questionnaire. If there is only one factor generated or the variance explanatory ratio of a certain common factor is dominant before rotation, there is a severe problem of single-source bias in the data. This study per- 
formed principal component analysis on all items on the questionnaire. Among the generated factors, the cumulative variance explanatory ratio of the factors with an eigenvalue greater than 1 was $57.257 \%$. The variance explanatory ratio of the first factor was $32.046 \%$, which is not dominant. In addition, this study strictly controlled the design and distribution of questionnaires, such as adopting simple and easy-tounderstand language when designing questions, informing participants that there was no right or wrong answer during the distribution of questionnaires, and assuring them that all information provided would be strictly confidential. Therefore, the problem of single-source bias in this study is rather small.

\section{$4 \quad$ Data Analysis and Results}

\subsection{Confirmatory factor analysis}

In order to test the discriminant validity between the key variables "entrepreneurial education," "entrepreneurial alertness," and "entrepreneurial intentions," and the measurement parameters of each variable scale, this study used AMOS 24.0 for confirmatory factor analysis of key variables. The results are as shown in Table 1. It is shown that compared with the two-factor model, single-factor model and zero model, the three-factor model is the best fit $(\chi 2(489)=1342.087, \mathrm{p}<0.01$; RMSEA $=0.051$, CFI $=0.901$, TLI $=0.908)$, indicating that the study model has good discriminant validity.

Table 1. Confirmatory Factor Analysis results

\begin{tabular}{|l|c|c|c|c|c|}
\hline \multicolumn{1}{|c|}{ Model } & $\boldsymbol{\chi}^{\mathbf{2}}$ & $\boldsymbol{d f}$ & RMSEA & TLI & CFI \\
\hline Zero model $^{\mathrm{a}}$ & 11261.219 & 528 & 0.172 & 0.000 & 0.000 \\
\hline Three-factor model $^{\prime}$ & 1342.087 & 489 & 0.051 & 0.901 & 0.908 \\
\hline Two-factor model $^{\mathrm{b}}$ & 1769.305 & 491 & 0.062 & 0.852 & 0.862 \\
\hline Two-factor model $^{\mathrm{c}}$ & 1630.773 & 491 & 0.059 & 0.868 & 0.877 \\
\hline Two-factor model $^{\mathrm{d}}$ & 1701.509 & 491 & 0.061 & 0.860 & 0.870 \\
\hline Single-factor model & \\
\hline
\end{tabular}

Note: $\mathrm{n}=692$;

${ }^{a}$ In the zero model, there is no relationship between all measured items

${ }^{\mathrm{b}}$ Combined entrepreneurial education and entrepreneurial alertness into one potential factor

${ }^{\mathrm{c}}$ Combined entrepreneurial intentions and entrepreneurial alertness into one potential factor

${ }^{\mathrm{d}}$ Combined entrepreneurial education and entrepreneurial intentions into one potential factor

${ }^{\mathrm{e}}$ Combined all items into one potential factor

\subsection{Descriptive statistical analysis of variables}

The mean and standard deviation of each variable as well as the correlation coefficients between variables are shown in Table 2. From Table 2, it can be seen that there is a significant positive correlation between entrepreneurship education and entrepreneurial alertness $(\mathrm{r}=0.430, \mathrm{p}<0.01)$ and entrepreneurial intentions $(\mathrm{r}=0.479, \mathrm{p}<0.01)$. 
Meanwhile, entrepreneurial alertness is positively correlated with entrepreneurial intentions $(\mathrm{r}=0.535, \mathrm{p}<0.01)$. As such, the results of the correlation analysis provided most of the hypotheses of this study with preliminary support, which established the basis for the subsequent regression analysis.

Table 2. Mean and standard deviation of and correlationsbetween each major variable $(\mathrm{N}=672)$

\begin{tabular}{|c|c|c|c|c|c|c|c|c|}
\hline Variable & 1 & 2 & 3 & 4 & 5 & 6 & 7 & 8 \\
\hline \multicolumn{9}{|l|}{ 1.Gender ${ }^{\mathrm{a}}$} \\
\hline 2.Hukou ${ }^{\mathrm{b}}$ & $0.138 * *$ & & & & & & & \\
\hline $\begin{array}{l}\text { 3.Somewhat } \\
\text { introverted per- } \\
\text { sonality }\end{array}$ & 0.008 & 0.056 & & & & & & \\
\hline $\begin{array}{l}\text { 4. Somewhat } \\
\text { extroverted } \\
\text { personality } \\
\end{array}$ & 0.045 & 0.012 & $-0.370 * *$ & & & & & \\
\hline $\begin{array}{l}\text { 5.Extroverted } \\
\text { personality } \\
\end{array}$ & -0.044 & $-0.085^{*}$ & $-0.348 * *$ & $-0.326^{* *}$ & & & & \\
\hline $\begin{array}{l}\text { 6.Entrepreneurial } \\
\text { education }\end{array}$ & $0.101 * *$ & 0.041 & $-0.156 * *$ & -0.016 & $0.132 * *$ & & & \\
\hline $\begin{array}{l}\text { 7.Entrepreneurial } \\
\text { alertness }\end{array}$ & -0.013 & -0.032 & $-0.157 * *$ & -0.027 & $0.101 * *$ & $0.430 * *$ & & \\
\hline $\begin{array}{l}\text { 8.Entrepreneurial } \\
\text { intentions }\end{array}$ & -0.055 & -0.060 & $-0.133 * *$ & 0.022 & 0.039 & $0.479 * *$ & $0.535^{* *}$ & \\
\hline Mean & 0.550 & 0.550 & 0.280 & 0.260 & 0.240 & 3.481 & 3.336 & 3.264 \\
\hline $\begin{array}{l}\text { Standard Devia- } \\
\text { tion }\end{array}$ & 0.498 & 0.498 & 0.451 & 0.438 & 0.424 & 0.678 & 0.739 & 0.806 \\
\hline
\end{tabular}

Note: $* * \mathrm{p}<0.01, * \mathrm{p}<0.05$

${ }^{\mathrm{a}}$ Gender: Male $=0$, Female $=1$; ${ }^{b}$ Hukou: Rural $=0$, Urban=1; ${ }^{\mathrm{c}}$ Somewhatintroverted personality: Introverted personality $=0$, Somewhatintroverted personality $=1$; ${ }^{\mathrm{d}}$ Somewhatextroverted personality: Introverted personality $=0$, Somewhatextroverted personality $=1$; Extroverted personality: Introverted personality $=0$, Extroverted personality $=1$.

\subsection{Hypothesis testing}

This study used hierarchical regression to test the hypothesis. The test results are shown in Table 3.

- The main effect. From Table 3, it is shown that entrepreneurial education has a significant positive effect on entrepreneurial intentions (M4, $\beta=0.488, \mathrm{p}<0.001)$. Therefore, Hypothesis 1 is supported.

- The mediating effect. From Table 3, it is shown that entrepreneurial education has a significant positive effect on entrepreneurial alertness (M2, $\beta=0.419, \mathrm{p}<0.001)$. Entrepreneurial alertness has a significant positive effect on entrepreneurial intentions (M5, $\beta=0.528, \mathrm{p}<0.001$ ). As mentioned previously, entrepreneurship education has a significant positive impact on entrepreneurial intentions. After introducing intermediary variables, the impact of entrepreneurial education on entrepreneurial intentions declined (M4 to M6, $\beta$ from 0.488 to $0.322, \mathrm{p}<0.001$ ), while en- 
trepreneurial alertness still has a significant influence on entrepreneurial intentions (M6, $\beta=0.395, \mathrm{p}<0.001$ ). Therefore, Hypothesis 2 is supported. Although the test method for mediating effect of Baron and Kenny (1986) is widely adopted, it was not able to test the significance of the mediating effect. Therefore, this study further used the Sobel method (Sobel, 1982) to decide whether the mediating effect was significant. The analysis results show that the mediating effect of entrepreneurial alertness in the relationship between entrepreneurial education and entrepreneurial intentions is significant $(Z=8.153, p<0.01)$. Therefore, Hypothesis 2 is further supported by data.

- Moderating effect. In order to eliminate collinearity, this study centralizes the independent variables and the modulating variables separately before constructing the product of these two variables. From Table 3, the interaction between entrepreneurial education and entrepreneurial alertness has a significant positive impact on entrepreneurial intentions. (M7, $\beta=0.101, \mathrm{p}<0.01$ ). Therefore hypothesis 3 is supported. The interaction model is shown in Figure 2.

Table 3. Results of Hierarchical Regression: The Impact of Entrepreneurial Education and Entrepreneurial Alertness on Entrepreneurial Intentions

\begin{tabular}{|c|c|c|c|c|c|c|c|}
\hline \multirow{2}{*}{$\begin{array}{c}\text { Variables } \\
\text { Control Variables } \\
\end{array}$} & \multicolumn{2}{|c|}{$\begin{array}{c}\text { Entrepreneurial } \\
\text { Alertness }\end{array}$} & \multicolumn{5}{|c|}{ Entrepreneurial Intentions } \\
\hline & $\mathrm{M}_{1}$ & $\mathrm{M}_{2}$ & $\mathrm{M}_{3}$ & $\mathrm{M}_{4}$ & $\mathrm{M}_{5}$ & $\mathrm{M}_{6}$ & $\mathrm{M}_{7}$ \\
\hline $\begin{array}{l}\text { Gender dummy variables (Fe- } \\
\text { male \& Male) }\end{array}$ & -0.004 & -0.047 & -0.047 & $-0.097 * *$ & -0.045 & $-0.078 *$ & $-0.083 * *$ \\
\hline $\begin{array}{l}\text { Hukou dummy variables (Urban } \\
\& \text { Rural) }\end{array}$ & -0.019 & -0.037 & -0.048 & $-0.068 *$ & -0.037 & -0.054 & $-0.068 *$ \\
\hline $\begin{array}{l}\text { Personality dummy variable } 1 \\
\text { (Somewhat introverted \& Intro- } \\
\text { verted) }\end{array}$ & $-0.191 * * *$ & $-0.126^{* *}$ & $\begin{array}{c}- \\
0.162 * * \\
\end{array}$ & $-0.086^{*}$ & -0.061 & -0.036 & -0.043 \\
\hline $\begin{array}{l}\text { Personality dummy variable } 2 \\
\text { (Somewhat extroverted \& } \\
\text { Introverted) }\end{array}$ & $-0.097 *$ & -0.073 & -0.048 & -0.021 & 0.003 & 0.008 & 0.000 \\
\hline $\begin{array}{l}\text { Personality dummy variable } 3 \\
\text { (Extroverted \& Introverted) }\end{array}$ & 0.001 & -0.027 & -0.039 & -0.072 & -0.040 & -0.062 & -0.071 \\
\hline \multicolumn{8}{|l|}{ Independent Variable } \\
\hline Entrepreneurial Education & & $0.419 * * *$ & & $0.488 * * *$ & & $0.322 * * *$ & $0.326 * * *$ \\
\hline \multicolumn{8}{|l|}{$\begin{array}{l}\text { Mediating variable and moderat- } \\
\text { ing variable }\end{array}$} \\
\hline Entrepreneurial Alertness & & & & & $0.528 * * *$ & $0.395 * * *$ & $0.385 * * *$ \\
\hline \multicolumn{8}{|l|}{ Interaction items } \\
\hline $\begin{array}{l}\text { Entrepreneurial Education* } \\
\text { Entrepreneurial Alertness }\end{array}$ & & & & & & & $0.101 * *$ \\
\hline $\mathrm{R}^{2}$ & 0.033 & 0.201 & 0.025 & 0.251 & 0.294 & 0.376 & 0.385 \\
\hline F value & $4.614 * * *$ & $27.925 * * *$ & $3.347 * *$ & $37.197 * * *$ & $46.131 * * *$ & $57.077 * * *$ & $\begin{array}{c}51.983 * * \\
*\end{array}$ \\
\hline$\Delta \mathrm{R}^{2}$ & 0.033 & 0.168 & 0.025 & 0.227 & 0.269 & 0.124 & 0.010 \\
\hline$\Delta \mathrm{F}$ & $4.614 * * *$ & $\begin{array}{c}139.678 * * \\
*\end{array}$ & $3.347 * *$ & $\begin{array}{c}201.411 * * \\
*\end{array}$ & $\begin{array}{c}253.701 * * \\
*\end{array}$ & $\begin{array}{c}132.292 * * \\
*\end{array}$ & $10.571 * *$ \\
\hline
\end{tabular}

Note: $* * * \mathrm{p}<0.001$ (bilateral), ${ }^{* *} \mathrm{p}<0.01$ (bilateral), $* \mathrm{p}<0.05$ (bilateral) 


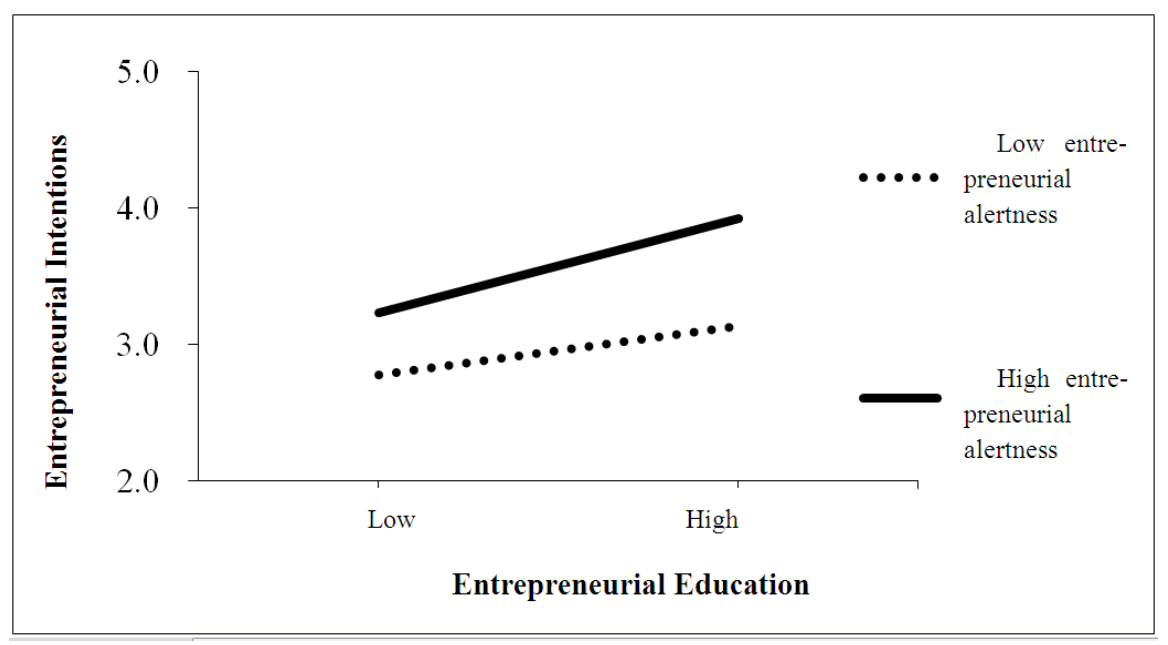

Fig. 2. Interactive effect between entrepreneurial education and entrepreneurial alertness

\section{Discussion and Conclusion}

According to the survey data of the university students in the Chinese provinces of Zhejiang and Fujian, this paper draws the following conclusions: First, there are no significant differences in the level of entrepreneurial intentions between genders and specialisations, but there is between regions; Second, the entrepreneurial education (acquisition) has a significant impact in promoting both entrepreneurial alertness and entrepreneurial intentions; Third, entrepreneurial alertness has a partial mediating effect between entrepreneurial education and entrepreneurial intentions, and enhancing entrepreneurial alertness will lead to generating higher entrepreneurial intentions; Fourth, entrepreneurial alertness moderated the promotion effect of entrepreneurial education (acquisition) on entrepreneurial intentions, and high alertness can amplify the promotion effect of entrepreneurial education (acquisition) on entrepreneurial intentions.

Entrepreneurial alertness is an ability to recognise opportunities, and is the result obtained after receiving entrepreneurial education. Constructing an entrepreneurial education system in multiple aspects can stimulate the generation of entrepreneurial intentions through improving the entrepreneurial alertness of college students.

According to the conclusions of the study, this paper, from the perspectives of stimulating entrepreneurial alertness and entrepreneurial intentions, will provide recommendations on the construction of entrepreneurial education (acquisition) system.

- Enrich the curriculum content of entrepreneurial education in all areas. Entrepreneurial education can be carried out through the transfer of knowledge of entrepreneurial values, entrepreneurial spirit, new business management, entrepreneurial practices, and even interpersonal skills. These can significantly enhance entrepreneurial intentions and entrepreneurial alertness. At the same time, it should also be 
noted that the entrepreneurial education system is not just a transmission of knowledge, but should also be supported by other measures.

- Establish a variety of extra-curricular lessons to stimulate entrepreneurial alertness and entrepreneurial intentions. Extra-curricular lessons enable college students to have more direct experiences in entrepreneurship. These extra-curricular lessons include case studies of a diversity of entrepreneurs, successful entrepreneurial role models, and real-life examples of youth entrepreneurship. These cases can allow college students to intuitively experience the entrepreneurial process. At the same time, inviting entrepreneurs to give lectures and speeches, as well as providing more opportunities for interviews with the business community can enable students to experience the entrepreneurial charisma and operational wisdom of the entrepreneurs first hand. That in combination with the organisation of entrepreneurial contests allows the discovery of new entrepreneurial talents among the students and also sets the bar for student entrepreneurship. These contests and discussions that resemble road shows enable students to learn more about the ways of selecting opportunities. The establishment of the above educational activities can enhance the college students' recognition awareness and analytical ability of opportunities, and their sensitivity to entrepreneurial opportunities, and can boost their aspiration for entrepreneurship and develop their courage to overcome difficulties, which will help them to generate more entrepreneurial intentions.

- In addition to curricular education, more resources should be provided as much as possible, and the integration of entrepreneurial resources should be promoted. The most prominent feature of entrepreneurial education is its high degree of practical operations. It is not sufficient to rely solely on curricular teaching and extracurricular learning, if more results are desired. There must be more support for entrepreneurial students and relevant resources to their needs. Specific examples include conducting formal or informal entrepreneurial counselling to provide entrepreneurial college students with timely advices. Additionally, the integration of the three main entrepreneurial resources - information, skills and financial capital has to be effectively promoted, such as encouraging and supporting college students to open an entrepreneurial salon to exchange information to in turn inspire more ideas, and forming organisations of entrepreneurial students where they could help one another. In the library, the specialised ability to utilise information can provide entrepreneurs with the convenience of accessing technology and the most authoritative business information. At the same time, the convenience and support of capital connection should be provided as much as possible.

\section{Reference}

[1] Azjen, I., 1991. The theory of planned behavior. Organizational Behavior \& Human Decision Processes 50, 179-211. https://doi.org/10.1016/0749-5978(91)90020-T

[2] Carayannis, E.G., Dan, E., Hanson, M., 2003. A cross-cultural learning strategy for entrepreneurship education: outline of key concepts and lessons learned from a comparative study of entrepreneurship students in France and the US. Technovation 23, 757-771. https://doi.org/10.1016/S0166-4972(02)00030-5 
[3] Elfving, J., Brännback, M., Carsrud, A., 2009. Toward A Contextual Model of Entrepreneurial Intentions. Springer New York. https://doi.org/10.1007/978-1-4419-0443$\underline{02}$

[4] Evans, A.J., Friedman, J., 2011. "SEARCH" VS. "BROWSE": A THEORY OF ERROR GROUNDED IN RADICAL (NOT RATIONAL) IGNORANCE. Critical Review 23, 73104. https://doi.org/10.1080/08913811.2011.574471

[5] Gaglio, C.M., Katz, J.A., 2001. The Psychological Basis of Opportunity Identification: Entrepreneurial Alertness. Small Business Economics 16, 95-111.

[6] https://doi.org/10.1023/A:1011132102464

[7] Gartner, W.B., Vesper, K.H., 1994. Experiments in entrepreneurship education: Successes and failures. Journal of Business Venturing 9, 179-187. https://doi.org/10.1016/08839026(94)90028-0

[8] Gimeno, J., Folta, T.B., Cooper, A.C., Woo, C.Y., 1997. Survival of the Fittest? Entrepreneurial Human Capital and the Persistence of Underperforming Firms. Administrative Science Quarterly 42, 750-783. https://doi.org/10.2307/2393656

[9] Jr, N.F.K., Reilly, M.D., Carsrud, A.L., 2000. Competing models of entrepreneurial intentions. Journal of Business Venturing 15, 411-432. https://doi.org/10.1016/S08839026(98)00033-0

[10] Kaish, S., Gilad, B., 1991. Characteristics of opportunities search of entrepreneurs versus executives: Sources, interests, general alertness $i$. Journal of Business Venturing 6, 4561. https://doi.org/10.1016/0883-9026(91)90005-X

[11] Kirzner, I.M., 1979. Perception, Opportunity, and Profit. University of Chicago Press, Chicago.

[12] Kirzner, I.M., 1985. Discovery and the capitalist process. Chicago : University of Chicago Press.

[13] Ko, S., Butler, J.E., 2007. Creativity: A key link to entrepreneurial behavior. Business Horizons 50, 365-372. https://doi.org/10.1016/j.bushor.2007.03.002

[14] Kolvereid, L., 1996. Prediction of employment status choice intentions. Entrepreneurship Theory \& Practice 21, 47-57. https://doi.org/10.1177/104225879602100104

[15] Krueger, N., 1993. The impact of prior entrepreneurial exposure on perceptions of new venture feasibility and desirability. Entrepreneurship: Theory and practice 18, 5-22. https://doi.org/10.1177/104225879301800101

[16] Leoni, T., Falk, M., 2010. Gender and Field of Study as Determinants of SelfEmployment. Small Business Economics 34, 167-185. https://doi.org/10.1007/s11187008-9114-1

[17] Li, Z., 2013. Entrepreneurial Alertness: An Exploratory Study. Springer Berlin Heidelberg. https://doi.org/10.1007/978-3-642-31098-0

[18] Ma, R., Huang, Y.-C., 2016. Opportunity-Based Strategic Orientation, Knowledge Acquisition, and Entrepreneurial Alertness: The Perspective of the Global Sourcing Suppliers in China. Journal of Small Business Management 54, 953-972.

[19] Mitchell, R.K., Smith, B., Seawright, K.W., Morse, E.A., 2000. Cross-Cultural Cognitions and the Venture Creation Decision. Academy of Management Journal 43, 974-993.

[20] Noel, T.W., 2002. Effects of entrepreneurial education on intent to open a business: an exploratory study. Journal of entrepreneurship education.

[21] Smith, B.R., Matthews, C.H., Schenkel, M.T., 2009. Differences in Entrepreneurial Opportunities: The Role of Tacitness and Codification in Opportunity Identification *. Journal of Small Business Management 47, 38-57. 
[22] Souitaris, V., Zerbinati, S., Al-Laham, A., 2007. Do entrepreneurship programmes raise entrepreneurial intention of science and engineering students? The effect of learning, inspiration and resources. Journal of Business Venturing 22, 566-591. https://doi.org/10.1016/j.jbusvent.2006.05.002

[23] Tang, J., Kacmar, K.M., Busenitz, L., 2012. Entrepreneurial alertness in the pursuit of new opportunities. Journal of Business Venturing 27, 77-94. https://doi.org/10.1016/j.jbusvent.2010.07.001

[24] Thompson, E.R., 2009. Individual Entrepreneurial Intent: Construct Clarification and Development of an Internationally Reliable Metric. Entrepreneurship Theory and Practice 33, 669-694. https://doi.org/10.1111/j.1540-6520.2009.00321.x

[25] TKACHEV, A., KOLVEREID, L., 1999. Self-employment intentions among Russian students. Entrepreneurship \& Regional Development 11, 269-280. https://doi.org/10.1080/089856299283209

[26] Uy, M.A., Chan, K.Y., Sam, Y.L., Ho, M.H.R., Chernyshenko, O.S., 2015. Proactivity, adaptability and boundaryless career attitudes: The mediating role of entrepreneurial alertness. Journal of Vocational Behavior 86, 115-123. https://doi.org/10.1016/j.jvb.2014.11.005

[27] Fu, H., Feng, X., Duan, J., 2010. The relationship between entrepreneurial alertness, team initiative and opportunity recognition among college students - A comparison of two entrepreneurial education models. Modern Education Management, 115-118.

[28] Li, G., Li, N., 2014. A study on the impact of indvidual traits on the entrepreneurial alertness of college student entrepreneurs - based on the moderating effect of social entrepreneurship policies. Educational Development Research, 38-43.

[29] Sun, L., 2016. Empirical study on the influencing factors of college students' willingness for continuous entrepreneurship - based on the perspective of TPB theory. Educational Development Research, 37-43.

[30] Tian, Y., Wang, H., 2011. Analysis of the entrepreneurship situation and influencing factors of college students abroad. Dynamics of Economics, 142-146.

[31] Wang, P., Lu, Q., 2015. The impact of entrepreneurial alertness, existing knowledge, and entrepreneurial experience on the entrepreneurial opportunity recognition of college students. Pschological Science, 160-165.

[32] Wei, X., 2009. Frontier analysis of entrepreneurial alertness and related propositions. Foreign Economics and Management, 8-14.

[33] Xiang, C., Lei, J., 2011. The relationship and influencing factors of entrepreneurial attitudes and tendencies among college students_- Taking Tsinghua University students as research object. Tsinghua University Educational Research 32, 55-55.

[34] Xiang, H., Lei, J., 2014. Research on the impact of college students' Entrepreneurial Education on Their Entrepreneurial Intentions. Tsinghua University Educational Research, 120-124.

[35] Zhu, H., Zhang, Y., 2014. The Mechanism of Entrepreneurship Education in Beijing Colleges and Universities Affecting the Students' entrepreneurial intentions: An Empirical Analysis Based on Student Participation and perspective. Tsinghua University Educational Research 35, 100-107. 
Paper-How does Entrepreneurial Education Influence the Entrepreneurial Intention of College..

\section{Authors}

Sang Dapeng is a lecturer of Wenzhou Business College, Wenzhou, China. Postcode.325035. His scientific interest are Entrepreneurship Management, Business Model and Strategic Management.

Jinyan Lin is from Yango University, Fuzhou, China. Email 729607714@qq.com

Article submitted 2019-02-25. Resubmitted 2019-03-20. Final acceptance 2019-03-28. Final version published as submitted by the authors. 